J. Amer. Soc. Hort. ScI. 115(4):575-580. 1990.

\title{
Lime and Phosphorus Effects on American Ginseng: II. Root and Leaf Ginsenoside Content and Their Relationship
}

\author{
T.R. Konsler ${ }^{1}$ \\ Department of Horticultural Science, North Carolina State University, Raleigh, NC 27695-7609 \\ S.W. Zito ${ }^{2}$ \\ Department of Pharmaceutical Sciences, St. John's University, Jamaica, New York 11439 \\ J.E. Shelton ${ }^{2}$ \\ Department of Soil Science, North Carolina State University, Raleigh, NC 27695-7619 \\ E.J. Staba ${ }^{3}$ \\ College of Pharmacy, University of Minnesota, Minneapolis, MN 55455 \\ Additional index words. Panax quinquefolium, soil fertility, root nutrients
}

\begin{abstract}
Soil-applied dolomitic limestone and fertilizer affected the level of certain root and leaf ginsenosides in 4year-old American ginseng (Panax quinquefolium L.); however, ginsenoside accumulations in the roots and in the leaves often were not similar. Root and leaf ginsenoside production tended to differ in its response to soil fertility (SF) factors and root tissue nutrient (RN) elements. Leaf ginsenoside production was more often correlated with SF factors and RN elements than that of root ginsenosides, the response of both ginsenoside sources was greater to RN than SF status. Leaf ginsenoside content was positively correlated with the SF factors and RN elements to a greater degree than that of root ginsenosides. Leaf ginsenoside production was more often affected by the same chemical element in the soil and in root tissue than that of root ginsenosides. There was no correlation between the level of any ginsenoside measured in root tissue and the same ginsenoside in leaf tissue.
\end{abstract}

Asian ginseng (Panax ginseng C.A. Meyer) has been an important constituent in traditional medicine of Oriental cultures for many centuries. American ginseng was introduced to China early in the 18th Century and has been exported to the Orient and used medicinally since that time.

An increased demand for American ginseng following World War II resulted in expansion of production in North America. Associated with the expansion has been an increase in scientific experimentation on cultural requirements of the crop. Crop nutritional studies have been based on mineral deficiency symptoms in sand culture (Stoltz, 1981, 1982a, 1982b) or on growth response to varying fertilization rates in field plots or container experiments (Konsler, 1979, 1980). Suspected B deficiency was based on the contrast in tissue B levels in normal and "rusty" roots (Proctor and Lee, 1983). SF and plant tissue nutrient levels associated with varying levels of crop performance have been used to judge fertilizer needs (Khwaja et al., 1984).

In recent years, saponin glycosides, commonly referred to as ginsenosides and implicated in the prevention and alleviation of stress and other health-related problems, have been identified in ginseng (Carr, 1986; Doughty, 1983; Shibata et al., 1986; Staba and Chan, 1979). Quantitative differences in total ginsenosides and qualitative and quantitative differences in individual ginsenosides between wild and cultivated plants have

Received for publication 13 Mar. 1989. Paper no. 12054 of the Journal Series of North Carolina Agricultural Research Service, Raleigh, NC 27695-7643. The technical assistance by George Cox, Ag. Res. Tech. I, is gratefully acknowledged. Mention of a proprietary product or of a vendor does not imply endorsement by North Carolina Agricultural Research Service or criticism of similar ones not mentioned. The cost of publishing this paper was defrayed in part by the payment of page charges. Under postal regulations, this paper therefore must be hereby marked advertisement solely to indicate this fact.

'Professor Emeritus.

${ }^{2}$ Associate Professor.

${ }^{3}$ Professor. been reported (Betz et al., 1984). Differences in moisture, nutrition, and other important factors of the growing environment cause great differences in rate of growth of wild and cultivated ginseng. Physiological stresses associated with differences in growth rate might also affect ginsenoside synthesis and accumulation.

If the efficacy of ginsenosides gains acceptance and becomes an important factor in use and marketing of ginseng, then it will become increasingly important to evaluate cultural variables as well as other factors (e.g., genetic differences, harvesting and postharvest handling techniques, processing procedures) for their influence on the various ginsenosides.

Only limited attention has been given to the possible impact of cultural or other environmental variables on ginsenoside content in American ginseng. Type of bed mulch affected content in leaves, but not in roots, of 4-year-old plants; both root and leaf content were affected at 7 years of age (Zito et al., 1986).

Zito et al. (1984) reported differences in root and leaf ginsenoside content of 4-year-old American ginseng due to soil $\mathrm{pH}$ and $\mathrm{P}$ differentials resulting from soil applications of dolomitic lime and superphosphate fertilizers. However, $\mathrm{pH}$ and $\mathrm{P}$ are only two of several SF factors that may be affected by lime and P fertilizer applications (Jackson, 1967). And while ginsenoside content may be statistically related to fertilizer treatments, the physiological behavior and biochemical reactions in ginseng would be more directly a response to fertility status of the soil or nutritional status within the plant than to fertilizers applied to the soil. Therefore, an examination of the relationship between SF or tissue nutrient status and ginsenoside content should suggest if and how ginsenoside levels might be influenced by fertilization practices.

American ginseng was grown in nursery pots from seed until

Abbreviations: RN, root tissue nutrients; SF; soil fertility; Tg, spectrophotometric measure of total ginsenosides. 
4 years old to determine 1 ) effect of dolomitic lime and $\mathrm{P}$ rates on root and leaf ginsenoside levels, 2) relationship of root and leaf ginsenoside contents to various SF factors, 3) relationship of root and leaf ginsenosides to various $\mathrm{RN}$, and 4) relationship between root ginsenosides and leaf ginsenosides.

\section{Materials and Methods}

Three rates each of dolomitic limestone $\left[\mathrm{Ca}-\mathrm{Mg}\left(\mathrm{CO}_{3}\right)_{2}\right]$ and superphosphate fertilizer $(0 \mathrm{~N}-8.7 \mathrm{P}-0 \mathrm{~K})$ were combined factorially in the RCB design experiment. The initial SF status, the materials and cultural procedures used, and growth responses were as reported previously (Konsler, 1979; Konsler and Shelton, 1990). Root and leaf tissue samples from five replicates were collected before the onset of leaf color change near the end of the fourth growing season. Samples were washed, dried in a forced-air oven at $80 \mathrm{C}$ to constant weight, and ground in a Wiley mill to pass a 40-mesh screen. Root and leaf samples from the five replicates were analyzed for ginsenoside content. Only root tissue was in adequate supply for tissue nutrient analyses; nutrient determinations were made on three of the five replicates (Agronomic Division, N.C. Dept. of Agr., Raleigh).

Tissue extraction for ginsenoside content was by the method of Chung (1978) with slight modification (Zito et al., 1984). The spectrophotometric method of Hiai et al. (1975) was used to determine the total ginsenosides ( $\mathrm{Tg}$ ) present, a composite of the nine or more individual ginsenosides identified in $P$. quinquefolium (Betz et al., 1984). Quantification of five individual ginsenosides (A1, Rg1, Rd, Re, and Rb2) used an HPLC column for carbohydrate analysis (Alltech Associates, Deerfield, Ill.). Total and individual ginsenosides were quantitated by direct comparison with referenced standards (Zito et al., 1984). All measurements were converted to percent (w/w) ginsenoside in the original sample of dried plant tissue. Multiple linear regression analyses (Steel and Torrie, 1960) were employed to examine lime and $\mathrm{P}$ effects on each ginsenoside. Regression and simple correlation analyses were based on the three replicates of the $3 \times 3$ factorial design $(N=27)$ from which $\mathrm{RN}$ determinations were made.

\section{Results and Discussion}

Ginsenoside response to lime and phosphorus. Lime and $\mathrm{P}$ additions resulted in significant changes in the tissue content of certain ginsenosides. Lime caused curvilinear responses in root $\mathrm{Tg}$, $\mathrm{Re}$, and $\mathrm{Rb} 2$, while $\mathrm{P}$ resulted in curvilinear responses in root $\mathrm{A} 1, \mathrm{Rg} 1, \mathrm{Re}$, and $\mathrm{Rb} 2$ (Table 1 ). Root $\mathrm{Tg}$ and $\mathrm{Re}$ were maximum at the median lime rate, whereas root $\mathrm{Rb} 2$ was minimum at the median rate. Root Rd was not affected by lime or $\mathrm{P}$ treatments. There was no interaction between lime and $\mathrm{P}$ in their effect on root ginsenosides.

Maximum root size was attained with the median liming rate (Konsler, 1980; Konsler and Shelton, 1990). Ginsenoside determinations were on a tissue concentration basis, thus the shape of the response curves for root $\mathrm{Sp}$ and Re suggests that synthesis and/or accumulation was enhanced by the median liming rate beyond enhancement in root growth. The response of root $\mathrm{Rb} 2$ to lime suggests that tissue dilution may have been the dominant factor relating tissue concentration with liming rate.

A biological explanation for the responses in root A1, Rg1, $\mathrm{Re}$, and $\mathrm{Rb} 2$ to $\mathrm{P}$ is not as evident. Growth response to $\mathrm{P}$ was positive and linear (Konsler, 1979, 1980; Konsler and Shelton, 1990); therefore, tissue dilution of the ginsenosides could not be the sole explanation for the relatively low levels of these
Table 1. Root ginsenoside response at 4 years to soil-applied lime and $\mathrm{P}$.

\begin{tabular}{|c|c|c|c|c|c|c|}
\hline \multirow{2}{*}{$\begin{array}{l}\text { Addition } \\
\left(\mathrm{kg} \cdot \mathrm{m}^{-3}\right)\end{array}$} & \multicolumn{6}{|c|}{ Ginsenoside $^{\mathrm{z}}(\%)$} \\
\hline & $\mathrm{Tg}$ & $\mathrm{A} 1$ & Rg1 & $\mathrm{Rd}$ & $\mathrm{Re}$ & $\mathrm{Rb} 2$ \\
\hline \multicolumn{7}{|l|}{ Lime } \\
\hline 0.0 & 1.70 & 0.50 & 0.22 & 0.06 & 0.25 & 0.029 \\
\hline 4.42 & 2.24 & 0.52 & 0.22 & 0.06 & 0.31 & 0.023 \\
\hline 8.84 & 2.09 & 0.52 & 0.21 & 0.07 & 0.27 & 0.027 \\
\hline \multicolumn{7}{|l|}{$\mathrm{P}$} \\
\hline 0.0 & 1.97 & 0.50 & 0.26 & 0.06 & 0.31 & 0.028 \\
\hline 0.16 & 1.98 & 0.47 & 0.20 & 0.06 & 0.25 & 0.022 \\
\hline 0.32 & 2.09 & 0.57 & 0.18 & 0.07 & 0.27 & 0.029 \\
\hline \multicolumn{7}{|l|}{ Significance } \\
\hline Lime & $\mathrm{L}^{\mathrm{a}} \mathrm{Q}^{\mathrm{b}}$ & NS & NS & NS & $\mathrm{L}^{\mathrm{a}} \mathrm{Q}^{\mathrm{a}}$ & $\mathrm{L}^{\mathrm{b}} \mathrm{Q}^{\mathrm{c}}$ \\
\hline $\mathrm{P}$ & NS & $\mathrm{L}^{c} \mathrm{Q}^{\mathrm{b}}$ & $\mathrm{L}^{\mathrm{a}} \mathrm{Q}^{\mathrm{c}}$ & NS & $\mathrm{L}^{\mathrm{a}} \mathrm{Q}^{\mathrm{b}}$ & $\mathrm{L}^{\mathrm{b}} \mathrm{Q}^{\mathrm{b}}$ \\
\hline Interaction ${ }^{\circ}$ & NS & NS & NS & NS & NS & NS \\
\hline $\mathrm{R}$ & $0.65^{a}$ & $0.65^{a}$ & $0.87^{\mathrm{a}}$ & NS & $0.79^{a}$ & $0.65^{b}$ \\
\hline
\end{tabular}

${ }^{\mathrm{A}} \mathrm{A} 1, \mathrm{Rg} 1, \mathrm{Rd}, \mathrm{Re}$, and $\mathrm{Rb} 2$ = HPLC measure of individual ginsenosides. [Ginsenoside values from Zito et al. (1984).]

$\mathrm{NS}, \mathrm{a}, \mathrm{b}, \mathrm{c}$ Nonsignificant or significant at $P=0.001,0.01$, or 0.05 , respectively. $\mathrm{L}=$ linear; $\mathrm{Q}=$ quadratic; $\mathrm{R}=$ multiple correlation coefficient.

Table 2. Leaf ginsenoside response at 4 years to soil-applied lime and $P$.

\begin{tabular}{|c|c|c|c|c|c|c|}
\hline \multirow{2}{*}{$\begin{array}{l}\text { Addition } \\
\left(\mathrm{kg} \cdot \mathrm{m}^{-3}\right)\end{array}$} & \multicolumn{6}{|c|}{ Ginsenoside $^{\mathrm{z}}(\%)$} \\
\hline & $\mathrm{Tg}$ & A1 & Rg1 & $\mathrm{Rd}$ & $\operatorname{Re}$ & $\mathrm{Rb} 2$ \\
\hline \multicolumn{7}{|l|}{ Lime } \\
\hline 0.0 & 2.92 & 0.52 & 0.19 & 0.32 & 0.54 & 0.37 \\
\hline 4.42 & 3.04 & 0.51 & 0.21 & 0.62 & 0.74 & 0.46 \\
\hline 8.84 & 2.82 & 0.60 & 0.28 & 0.37 & 0.51 & 0.49 \\
\hline \multicolumn{7}{|l|}{$\mathrm{P}$} \\
\hline 0.0 & 2.27 & 0.52 & 0.19 & 0.37 & 0.55 & 0.33 \\
\hline 0.16 & 3.08 & 0.56 & 0.23 & 0.46 & 0.66 & 0.50 \\
\hline 0.32 & 3.43 & 0.54 & 0.26 & 0.44 & 0.58 & 0.49 \\
\hline \multicolumn{7}{|l|}{ Significance } \\
\hline Lime & NS & NS & $Q^{a}$ & $\mathrm{~L}^{\mathrm{a}} \mathrm{Q}^{\mathrm{a}}$ & $\mathrm{L}^{\mathrm{a}} \mathrm{Q}^{\mathrm{a}}$ & $\mathrm{L}^{\mathrm{b}}$ \\
\hline $\mathrm{P}$ & $\mathrm{L}^{\mathrm{a}}$ & NS & $\mathrm{L}^{\mathrm{a}}$ & $\mathrm{L}^{\mathrm{a}}$ & $\mathrm{L}^{\mathrm{b}} \mathrm{Q}^{\mathrm{c}}$ & $\mathrm{L}^{\mathrm{b}} \mathrm{Q}^{\mathrm{c}}$ \\
\hline Interaction & NS & NS & NS & b & $\mathrm{b}$ & c \\
\hline $\mathrm{R}$ & $0.61^{\mathrm{a}}$ & NS & $0.80^{a}$ & $0.85^{\mathrm{a}}$ & $0.84^{\mathrm{a}}$ & $0.71^{\mathrm{b}}$ \\
\hline
\end{tabular}

${ }^{z} \mathrm{~A} 1, \mathrm{Rg} 1, \mathrm{Rd}, \mathrm{Re}$, and $\mathrm{Rb} 2$ = HPLC measure of individual ginsenosides. [Ginsenoside values from Zito et al. (1984).]

NS,a,b,c Nonsignificant or significant at $P=0.001,0.01$, or 0.05 , respectively. $\mathrm{L}=$ linear; $\mathrm{Q}=$ quadratic; $\mathrm{R}=$ multiple correlation coefficient.

ginsenosides at the mid-P rate. A nonlinear direct effect of $\mathrm{P}$ on synthesis and/or accumulation of the ginsenosides, or a nonlinear effect interacting with the effect on root size, may have caused the results obtained.

Leaf ginsenosides also were affected by lime and $\mathrm{P}$ treatments; however, responses in the two plant parts were dissimilar in most respects. Lime caused curvilinear responses in leaf $\mathrm{Rg} 1$, $\mathrm{Rd}$, and $\mathrm{Re}$ (Table 2); neither Rg1 nor Rd in root tissue was affected by lime (Table 1). Phosphorus treatments resulted in positive linear responses in leaf $\mathrm{Tg}, \mathrm{Rg} 1$, and $\mathrm{Rd}$ and curvilinear responses in leaf $\mathrm{Re}$ and $\mathrm{Rb} 2$ (Table 2 ). Both $\mathrm{Re}$ and $\mathrm{Rb} 2$ were maximum at the mid-P rate. In contrast, only $\mathrm{Rg} 1, \mathrm{Re}$, and $\mathrm{Rb} 2$ in root tissue were affected by $\mathrm{P}$; all with relatively low levels at the mid-P rate (Table 1 ).

Ginsenoside response to soil fertility factors. Application of lime and $\mathrm{P}$ fertilizer affected not only $\mathrm{pH}$ and $\mathrm{P}$ levels in the soil, but also the level of other essential plant nutrient elements as well (Konsler and Shelton, 1990). 
Simple correlations were calculated between the six ginsenoside quantities ( $\mathrm{Tg}$ and the five individual ginsenosides) in root and leaf tissue and each of the eight SF factors to identify those factors related to the various ginsenosides in the two tissue sources. The correlations associated with a particular factor varied with ginsenoside and with tissue source (Table 3). For example, soil $\mathrm{pH}$ was correlated only with root $\mathrm{Tg}$ and leaf $\mathrm{Rg} 1$; each was positive. Thus, within the range of $\mathrm{PH}$ variation, total root ginsenoside increased with soil $\mathrm{pH}$, while the individual root ginsenosides measured were independent of $\mathrm{pH}$. Also, leaf Rg1 increased with $\mathrm{pH}$, while other individual and total leaf ginsenosides were not related to soil acidity. Soil $\mathrm{P}$ was positively correlated with root $\mathrm{Al}$ and leaf $\mathrm{Tg}, \mathrm{Rg} 1$, and $\mathrm{Rb} 2$; it was negatively correlated with root $\mathrm{Rg} 1$. Of special curiosity was the opposing sign of the correlations of $\mathrm{P}$ with root and leaf $\mathrm{Rg} 1$, implying opposite effects of $\mathrm{pH}$ in the two plant parts. Only in a few instances was a ginsenoside in both tissue sources similarly related to a SF factor; for example, soil Na was positively correlated with both root and leaf $\mathrm{Tg}$, and soil Mn was negatively correlated with both root and leaf Re.

Certain other consistencies were evident in the results. For example, soil $\mathrm{pH}, \mathrm{K}$, and $\mathrm{Ca}$ had the same pattern of significant correlations with root and leaf ginsenosides; each was positively correlated with root $\mathrm{Tg}$ and leaf $\mathrm{Rg} 1$ (Table 3). The agreement in correlation with $\mathrm{pH}$ and $\mathrm{Ca}$ would not be surprising, since each of these factors was directly related to liming rate. Such correlations among SF factors would interfere with interpretation of cause/effect relationships.

The incidence of significant correlations in Table 3 and the qualitative differences (positive vs. negative) associated with root and leaf ginsenosides were summarized to demonstrate general similarities and contrasts in "correlation activity" in the two plant tissue sites. Of the 48 combinations (eight SF factors $\times$ six ginsenosides), $19(40 \%)$ produced significant correlations with root and/or leaf ginsenosides (Table 4). Eight combinations (17\%) were significant with root ginsenosides and $15(31 \%)$ with leaf ginsenosides. Four of the eight root correlations (50\%) were positive while 13 of the 15 involving leaves $(87 \%)$ were positive. Four of the eight root correlations (50\%) also were associated with significant leaf correlations; in one of these cases
(25\%), the correlations were of like sign, and in three $(75 \%)$ of unlike sign.

Conclusions indicated by these data are: 1) SF factors were more closely related to leaf than to root ginsenoside concentrations, 2) correlations involving root ginsenosides were equally balanced between positive and negative quantities, whereas those involving leaf ginsenosides were predominately positive, and 3) there was no suggestion of a relationship between root and leaf ginsenoside accumulation.

Ginsenoside response to root nutrient elements. Simple correlations were calculated between the six measures of ginsenosides in root and leaf tissue and each of the nine RN elements to identify those tissue elements significantly related to ginsenoside concentration in the two tissue sources. As with the SF factors, there were patterns of similarity in the correlations generated with RN elements (e.g., root $\mathrm{Mn}$ and $\mathrm{Zn}$ produced precisely the same pattern of correlations with root ginsenosides and with leaf ginsenosides) but also a great deal of dissimilarity [e.g., root $\mathrm{N}$ was negatively correlated with root $\mathrm{Rg} 1$ and positively correlated with leaf Rg1 (Table 5)]. The greater proportion of significant correlations in Table $5(34 \%)$ than in Table $3(23 \%)$ suggests a closer relationship of plant ginsenosides production with plant nutritional status than with SF status. Also, the general paucity of quantitative and/or qualitative agreement in the tissue source correlations (Tables 3 and 5) suggests a relative independence of effect of either the soil or plant chemistry on ginsenoside content in the two tissue sources.

The correlation activity between RN and root and leaf ginsenosides is summarized in Table 6 . Of the 54 combinations (nine RN elements $\times$ six ginsenosides), 31 (57\%) produced significant correlations with root and/or leaf ginsenosides. Twelve (22\%) were associated with root ginsenosides and 25 (46\%) with ginsenosides in the leaves. Seven of the 12 root correlations $(58 \%)$ were positive, while 21 of those involving leaves $(84 \%)$ were positive. Six of the 12 significant root correlations $(50 \%)$ were associated with significant leaf correlations; one-half of these were of like sign and one-half of unlike sign.

Conclusions indicated by these data are: 1) RN elements were more closely related to leaf than to root ginsenoside concentration, 2) correlations involving root ginsenosides were nearly

Table 3. Simple correlation coefficients between SF factors and ginsenoside levels in root and leaf tissue of 4-year-old American ginseng.

\begin{tabular}{clllcrrr}
\hline \hline \multirow{2}{*}{$\begin{array}{c}\text { Soil fertility } \\
\text { factor }\end{array}$} & \multicolumn{7}{c}{ Ginsenoside } \\
\cline { 2 - 7 } & Source & $\mathrm{Tg}$ & $\mathrm{A} 1$ & $\mathrm{Rg} 1$ & $\mathrm{Rd}$ & $\mathrm{Re}$ & $\mathrm{Rb} 2$ \\
\hline $\mathrm{pH}$ & Root & $0.45^{*}$ & 0.10 & -0.06 & 0.19 & 0.18 & -0.10 \\
& Leaf & -0.08 & 0.30 & $0.59^{* *}$ & 0.08 & -0.10 & 0.31 \\
$\mathrm{P}$ & Root & 0.18 & $0.44^{*}$ & $-0.84^{* *}$ & 0.12 & -0.37 & 0.14 \\
& Leaf & $0.57^{* *}$ & 0.05 & $0.50^{* *}$ & 0.26 & 0.02 & $0.39^{*}$ \\
$\mathrm{~K}$ & Root & $0.51^{* *}$ & 0.24 & 0.13 & 0.31 & 0.36 & 0.11 \\
& Leaf & -0.09 & 0.24 & $0.54^{* *}$ & -0.02 & -0.16 & 0.25 \\
$\mathrm{Ca}$ & Root & $0.43^{*}$ & 0.15 & -0.16 & 0.23 & 0.10 & -0.06 \\
& Leaf & -0.01 & 0.30 & $0.68^{* *}$ & 0.07 & -0.14 & 0.36 \\
$\mathrm{Mg}$ & Root & 0.34 & 0.09 & -0.01 & 0.25 & 0.34 & 0.02 \\
& Leaf & -0.31 & 0.17 & $0.39^{*}$ & -0.08 & -0.32 & -0.02 \\
$\mathrm{Mn}$ & Root & -0.36 & 0.10 & -0.25 & -0.01 & $-0.62^{* *}$ & 0.34 \\
& Leaf & 0.18 & 0.20 & 0.34 & $-0.51^{* *}$ & $-0.50^{* *}$ & 0.17 \\
$\mathrm{Zn}$ & Root & 0.02 & 0.22 & -0.18 & -0.08 & -0.03 & -0.09 \\
& Leaf & $0.47^{*}$ & -0.31 & -0.28 & $0.49^{* *}$ & $0.55^{* *}$ & 0.11 \\
$\mathrm{Na}$ & Root & $0.56^{* *}$ & 0.32 & $-0.62^{* *}$ & 0.23 & -0.09 & -0.12 \\
& Leaf & $0.44^{*}$ & 0.18 & $0.69^{* *}$ & 0.35 & 0.15 & $0.62^{* *}$ \\
\hline
\end{tabular}

${ }^{\mathrm{z}} \mathrm{A} 1, \mathrm{Rg} 1, \mathrm{Rd}, \mathrm{Re}$, and $\mathrm{Rb} 2=\mathrm{HPLC}$ measure of individual ginsenosides.

**** Significant at $P=0.01$ or 0.05 , respectively. 
Table 4. Correlation activity ${ }^{2}$ between eight SF factors $\times$ six ginsenoside quantities in roots and leaves of 4-year-old American ginseng.

\begin{tabular}{lrrrr}
\hline & \multicolumn{3}{c}{ Significant correlations } \\
\cline { 2 - 5 } Ginsenoside source & \multicolumn{2}{c}{ No. } & \multicolumn{2}{c}{ Percent } \\
\hline Total & 19 & & 40 & \\
Root & 8 & & 17 & \\
$\quad+$ & & 4 & & 50 \\
- & & 4 & & 50 \\
Leaf & 15 & & 31 & \\
$\quad+$ & & 13 & & 87 \\
- & & 2 & & 13 \\
Root + leaf & 4 & & 50 & \\
$\quad$ Like sign & & 1 & & 25 \\
Unlike sign & & 3 & & 75 \\
\hline
\end{tabular}

${ }^{2}$ Number and percent of significant correlations $(P \leq 0.05)$.

equally balanced between positive and negative quantities, whereas those involving leaf ginsenosides were predominately positive, and 3 ) there was little indication of a relationship between root and leaf ginsenoside content.

Soil fertility vs. root nutrient interaction with ginsenosides. The correlation activity data suggested greater interaction of root and leaf ginsenosides with RN elements than with SF factors (Tables 6 and 4, respectively); however, a direct comparison of data in these tables is not possible, since the array of nutritional factors analyzed in the two sites was not identical. A direct comparison was made possible by restricting the comparison to correlations in Tables 3 and 5 involving the six chemical elements ( $\mathrm{P}, \mathrm{K}, \mathrm{Ca}, \mathrm{Mg}, \mathrm{Mn}$, and $\mathrm{Zn}$ ) that were common to both the soil and root tissue analyses.

Ten of the 36 correlations $(28 \%)$ involving the six root ginsenosides and the six SF and/or RN elements were significant (Table 7). Five (14\%) were associated with SF factors, while eight $(22 \%)$ were associated with $\mathrm{RN}$ elements. Three of the five-SF correlations $(60 \%)$ were positive, while five of the eight associated with RN elements $(62 \%)$ were positive. Three of the five significant correlations $(60 \%)$ involving SF elements also involved RN elements; all $(100 \%)$ were of like sign.

Twenty-three of the 36 correlations $(64 \%)$ between leaf ginsenosides and the six soil and/or root tissue elements were significant (Table 7). Twelve (33\%) were associated with SF elements and $20(56 \%)$ with RN elements. Ten of the $12(83 \%)$ significant correlations between leaf ginsenosides and the SF elements were positive, while 16 of the 20 involving RN elements $(80 \%)$ were positive. Nine of the 12 correlations (75\%) associated with SF elements also were significantly associated with RN elements; seven of the nine $(78 \%)$ were of like sign and two $(22 \%)$ of unlike sign.

There was greater correlation activity between soil or root tissue elements and leaf ginsenosides than with root ginsenosides (Table. 7). Total activity (SF and/or RN) with root ginsenosides was $28 \%$, whereas with leaf ginsenosides, total activity was $64 \%$. Leaf ginsenosides had a greater incidence of significant correlations than root ginsenosides with SF elements (33\% vs. $14 \%$ ) and RN elements (56\% vs. $22 \%$ ), a greater incidence of positive correlations with SF elements (83\% vs. 60\%) and RN elements ( $80 \%$ vs. $62 \%)$, and a greater tendency for simultaneous significance with the same element in the soil and in root tissue ( $75 \%$ vs. $60 \%$ ). Conclusions suggested by these data are: 1) the six RN elements were more closely related with both root and leaf ginsenoside content than the same SF elements, but the relationship of either element source was greater with leaf than with root ginsenoside content; 2) RN and SF elements were positively correlated with root ginsenoside concentration to an equal degree, the same was true with leaf ginsenosides; however, the positive association was greater with leaf than with root ginsenosides; and 3) there was a higher incidence of simultaneously significant correlations of leaf ginsenoside content with the same element in the soil and in root tissue than of root ginsenosides, but with either tissue source, the correlations generally were of like sign. The high incidence of simultaneously significant correlations of ginsenoside content with SF and RN elements of like sign (Table 7) suggests a similar reaction to

Table 5. Simple correlation coefficients between RN elements and ginsenoside levels in root and leaf tissue of 4-year-old American ginseng.

\begin{tabular}{clllrrrr}
\hline \hline \multirow{2}{*}{$\begin{array}{c}\text { Root nutrient } \\
\text { element }\end{array}$} & \multicolumn{7}{c}{ Ginsenoside $^{z}$} \\
\cline { 2 - 8 } $\mathrm{N}$ & Source & $\mathrm{Tg}$ & $\mathrm{A} 1$ & \multicolumn{1}{c}{$\mathrm{Rg} 1$} & $\mathrm{Rd}$ & $\mathrm{Re}$ & $\mathrm{Rb} 2$ \\
\hline $\mathrm{N}$ & Root & 0.29 & 0.09 & $-0.53^{* *}$ & -0.12 & -0.34 & 0.11 \\
$\mathrm{P}$ & Leaf & 0.26 & $0.45^{*}$ & $0.52^{* *}$ & 0.10 & 0.00 & 0.35 \\
& Root & $0.55^{* *}$ & 0.23 & $-0.56^{* *}$ & 0.15 & -0.15 & -0.19 \\
$\mathrm{~K}$ & Leaf & $0.45^{*}$ & 0.27 & $0.71^{* *}$ & $0.39^{*}$ & 0.25 & $0.69^{* *}$ \\
& Root & $0.61^{* *}$ & 0.15 & -0.30 & 0.03 & 0.03 & -0.25 \\
$\mathrm{Ca}$ & Leaf & 0.30 & 0.31 & $0.56^{* *}$ & $0.46^{*}$ & 0.35 & $0.57^{* *}$ \\
& Root & $0.54^{* *}$ & 0.37 & -0.32 & 0.15 & -0.06 & -0.12 \\
$\mathrm{Mg}$ & Leaf & $0.42^{*}$ & 0.31 & $0.78^{* *}$ & $0.43^{*}$ & 0.23 & $0.67^{* *}$ \\
& Root & $0.74^{* *}$ & $0.46^{*}$ & -0.24 & 0.32 & 0.14 & -0.07 \\
$\mathrm{Mn}$ & Leaf & $0.59^{* *}$ & $\mathbf{0 . 1 3}$ & $0.70^{* *}$ & $0.49^{* *}$ & $0.43^{*}$ & $0.80^{* *}$ \\
& Root & $-0.58^{* *}$ & -0.15 & 0.05 & -0.19 & -0.35 & 0.32 \\
$\mathrm{Cu}$ & Leaf & -0.01 & -0.17 & $-0.50^{* *}$ & $-0.44^{*}$ & -0.22 & -0.35 \\
& Root & 0.18 & -0.25 & $0.40^{*}$ & -0.03 & 0.10 & -0.18 \\
$\mathrm{Zn}$ & Leaf & 0.04 & 0.09 & -0.06 & 0.04 & 0.33 & 0.27 \\
& Root & $-0.48^{*}$ & -0.20 & 0.08 & -0.22 & -0.32 & 0.31 \\
$\mathrm{Fe}$ & Leaf & 0.02 & -0.12 & $-0.51^{* *}$ & $-0.40^{*}$ & -0.12 & -0.29 \\
& Root & 0.29 & $0.48^{*}$ & $-0.58^{* *}$ & 0.04 & -0.36 & 0.34 \\
& Leaf & $0.74^{* *}$ & 0.13 & $0.39^{*}$ & 0.19 & 0.19 & $0.53^{* *}$ \\
\hline
\end{tabular}

${ }^{\mathrm{x}} \mathrm{1}, \mathrm{Rg} 1, \mathrm{Rd}, \mathrm{Re}$, and $\mathrm{Rb} 2=\mathrm{HPLC}$ measure of individual ginsenosides.

**,*Significant at $P=0.01$ or 0.05 , respectively. 
Table 6. Correlation activity ${ }^{z}$ between nine $R N$ elements $\times$ six ginsenoside quantities in roots and leaves of 4-year-old American ginseng.

\begin{tabular}{|c|c|c|}
\hline \multirow[b]{2}{*}{ Ginsenoside source } & \multicolumn{2}{|c|}{ Significant correlations } \\
\hline & No. & Percent \\
\hline Total & 31 & 57 \\
\hline Root & 12 & 22 \\
\hline+ & 7 & 58 \\
\hline- & 5 & 42 \\
\hline Leaf & 25 & 46 \\
\hline+ & 21 & 84 \\
\hline- & 4 & 16 \\
\hline Root + leaf & 6 & 50 \\
\hline Like sign & 3 & 50 \\
\hline Unlike sign & 3 & 50 \\
\hline
\end{tabular}

${ }^{z}$ Number and percent of significant correlations $(P \leq 0.05)$.

Table 7. Correlation activity between six root or leaf ginsenoside quantities and six common nutrient elements ${ }^{z}$ in the soil (SF) or in the root tissue (RN) of 4-year-old American ginseng.

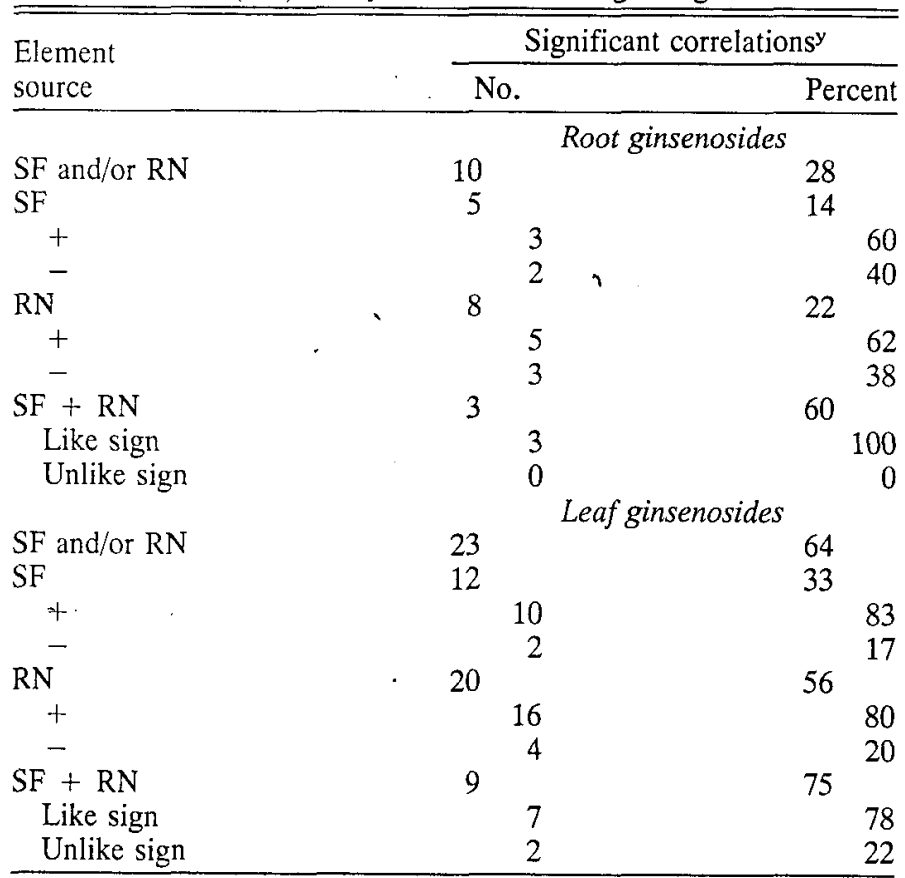

${ }^{2}$ Common elements were $\mathrm{P}, \mathrm{K}, \mathrm{Ca}, \mathrm{Mg}, \mathrm{Mn}$, and $\mathrm{Zn}$.

y Number and percent of significant $(P \leq 0.05)$ correlations.

the chemistry of the soil and of the roots in the accumulation of specific ginsenosides.

Root ginsenosides vs. leaf ginsenosides. In those cases where gensenoside content in roots and leaves was simultaneously correlated with SF factors (Table 4) or RN elements (Table 6), the correlations were of unlike sign at least as often as like sign, suggesting relative independence in the occurrence of like gensenosides in the two sites. To determine directly the degree of association between ginsenoside content in root and leaf tissue, simple correlations were computed between levels in the two plant parts. Of the 36 correlations, eight were significant (Table 8). Of the eight, five were associated with $\mathrm{Tg}$ in roots and/or leaves; root $\mathrm{Tg}$ was positively correlated with leaf $\mathrm{Rd}, \mathrm{Re}$, and $\mathrm{Rb} 2$, while leaf $\mathrm{Tg}$ was positively correlated with root $\mathrm{A} 1$ and negatively correlated with root $\mathrm{Rg} 1$. Among the five individual ginsenosides, the correlations between content in root and leaf tissue (25 combinations) were significant in only three cases;
Table 8. Simple correlations between six measures of root and leaf ginsenosides ${ }^{z}$ in 4-year-old American ginseng.

\begin{tabular}{lcccccc}
\hline \hline & \multicolumn{7}{c}{ Leaf } \\
\cline { 2 - 7 } Root & $\mathrm{Tg}$ & $\mathrm{A} 1$ & $\mathrm{Rg} 1$ & $\mathrm{Rd}$ & $\mathrm{Re}$ & $\mathrm{Rb} 2$ \\
\hline $\mathrm{Tg}$ & 0.34 & -0.01 & 0.36 & $0.49^{* *}$ & $0.51^{* *}$ & $0.54^{* *}$ \\
$\mathrm{~A} 1$ & $0.47^{*}$ & -0.16 & $0.43^{*}$ & 0.25 & 0.21 & $0.47^{*}$ \\
$\mathrm{Rg} 1$ & $-0.45^{*}$ & -0.01 & -0.34 & -0.13 & -0.03 & -0.32 \\
$\mathrm{Rd}$ & 0.11 & -0.12 & 0.37 & 0.05 & 0.01 & 0.29 \\
$\mathrm{Re}$ & -0.21 & -0.27 & -0.08 & 0.19 & 0.19 & -0.10 \\
$\mathrm{Rb} 2$ & 0.01 & 0.18 & -0.01 & -0.37 & $-0.46^{*}$ & -0.24 \\
\hline${ }^{2} \mathrm{~A} 1, \mathrm{Rg} 1, \mathrm{Rd}, \mathrm{Re}$, and $\mathrm{Rb} 2=$ individual ginsenosides; determinations \\
by HPLC. \\
**,*Significant at $P=0.01$ or 0.05 , respectively.
\end{tabular}

root A1 was positively correlated with leaf $\mathrm{Rg} 1$ and $\mathrm{Rb} 2$, and root $\mathrm{Rb} 2$ was negatively correlated with leaf Re. Neither the total gensenoside content nor content of any individual ginsenoside in root tissue was correlated with content of the same gensenoside in leaf tissue (Table 8). The relative independence of ginsenoside content in roots and leaves raises interesting questions about the site and control of mechanisms for synthesis, transport, and storage of these compounds in various parts of the ginseng plant.

The data presented have led to several conclusions concerning relationships between ginseng plant fertilization and nutrition and ginsenoside content in roots and leaves. These conclusions are: 1) ginsenoside content in roots and leaves was more closely related to nutritional status within the plant than to fertility status of the medium in which the plant grew; 2) leaf ginsenoside content was more closely related to and positively correlated with elements of SF or RN than to root ginsenoside content; 3) common elements of SF and tissue nutrient status were similar in their relationship with root ginsenosides and leaf ginsenosides; and 4) ginsenoside content in root tissue was highly independent of content in leaf tissue.

That ginsenoside level should be more closely related to tissue nutrient status than to SF status is not surprising. Plant nutritional status is influenced by SF; however, chemical reactions within plants are directly a function of the chemistry of the plant and secondarily of the soil.

The closer relationship between plant or soil chemistry and leaf than root ginsenoside content was not anticipated. Medicinal use of ginseng, studies concerning ginsenoside chemistry and pharmacology, and the production and economics of ginseng traditionally have focused on the roots. We found no studies reporting the role of the leaves in ginsenoside synthesis and storage. The data resulting from this study suggest the possibility that certain of the ginsenosides are largely, or totally, synthesized in leaf tissue with their synthesis and/or storage in the leaves being influenced by the nutritional status of the plant.

Independence of ginsenoside levels between roots and leaves also was not anticipated. In fact, just the opposite was expected, with root ginsenoside monitoring or prediction from leaf sample analyses being a convenient consequence. Possible explanations for the site independence in ginsenoside content include: 1) conditions that influence ginsenoside synthesis in the roots and leaves are largely independent; 2) transport to and/or storage in roots of ginsenosides synthesized in the leaves, as theorized earlier, is controlled by mechanisms different than those acting on the leaves.

Additional studies are needed to elucidate more definitively the relationships between tissue nutrient status and ginsenoside 
content in various parts of the ginseng plant. The current study dealt with the HPLC measure of total ginsenosides and five of the individual ginsenosides. At least four additional individual ginsenosides have been identified in $P$. quinquefolium; these also should be examined.

Leaf samples for ginsenoside analyses were taken in late summer, before leaf color change. Ginsenosides measured were equal to or greater in leaves than in roots; however, plant age and seasonal stage of development or maturation and proximity of leaf senescence may affect ginsenoside levels in the tops and roots. Correlations between levels found in roots and leaves should be based on leaf samples taken at a variety of times during the growing season and even in years before harvest maturity. For the current study, tissue nutrient status was based on root tissue analyses. While close correlation between RN and leaf tissue nutrient status would be expected, this has not been verified in ginseng. Such correlations need to be determined and/or ginsenoside levels in roots and leaves need to be examined as functions of nutrient status of the leaves.

\section{Literature Cited}

Betz, J.M., A.H. Der Morderosian, and T.M. Lee. 1984. Continuing studies on the ginsenoside content of commercial ginseng products by TLC and HPLC, II. Proc. 6th N. Amer. Ginseng Conf., Guelph, Ontario. p. 65-83.

Carr, C.J. 1986. Natural plant products that enhance performance and endurance. Proc. 7th N. Amer. Ginseng Conf., Delhi, N.Y. p. 1771.

Chung, N.J. 1978. The effect of ginseng saponins on several enzymes. Proc. 2nd Intl. Ginseng Symp., Seoul, Korea. p. 115-134.

Doughty, R.M. 1983. Ginseng: Legendary panacea. Proc. 5th Natl. Ginseng Conf., Lexington, Ky. p. 4-10.

Hiai, S., H. Oura, Y. Odaka, and T. Nakajima. 1975. A calorimetric estimation of ginseng saponins. Planta Medica, 28:363.

Jackson, W.A. 1967. Physiological effects of soil acidity. Soil acidity and liming. Amer. Soc. Agron. Madison, Wis. p. 43-124.
Khwaja, A., R. Roy, and M.A. Rouf. 1984. Ginseng (Panax quinquefolium L.) plant tissue, roots and soil testing for fertilizer recommendations. Proc. 6th N. Amer. Ginseng Conf., Guelph, Ontario. p. 116-138.

Konsler, T.R. 1979. Research with American ginseng (Panax quinquefolium L.) in North Carolina. Proc. 1st Natl. Ginseng Conf., Lexington, Ky. p. 79-90.

Konsler, T.R. 1980. An update on research with American ginseng (Panax quinquefolium L.) in North Carolina. Proc. 2nd Natl. Ginseng Conf., Jefferson City, Mo. p. 68-77.

Konsler, T.R. and J.E. Shelton. 1990. Lime and phosphorus effects on American ginseng: I. Growth, soil fertility, and tissue nutrient status response. J. Amer. Soc Hort. Sci. 115(4):570-574.

Proctor, J.T.A. and J.C. Lee. 1983. Some aspects of low temperature tolerance and mineral nutrition of American ginseng, Panax quinquefolium L. Proc. 5th Natl. Ginseng Conf., Lexington, Ky. p. 6269.

Shibata, S., O. Tanaka, J. Shoji, and H. Saito. 1986. Pharmacology and biochemistry of ginseng. Proc. 7th N. Amer. Ginseng Conf., Delhi, N.Y. p. 73-92.

Staba, E.J. and S.E. Chan. 1979. An overview of ginseng chemistry, pharmacology and anti-tumor effects. Proc. 1st Natl. Ginseng Conf., Lexington, Ky. p. 91-100.

Steel, R.G.D. and J.H. Torrie. 1960. Principles and procedures of statistics. McGraw-Hill, New York.

Stoltz, L.P. 1981. Effects of mineral elements on growth of American ginseng. Proc. 3rd Natl. Ginseng Conf., Asheville, N.C. p. 26-28.

Stoltz, L.P. 1982a. Leaf symptoms, yield, and composition of mineraldeficient American ginseng. HortScience 17(5):740-741.

Stoltz, L.P. 1982b. Mineral nutrition studies of American ginseng. Proc. 4th Natl. Ginseng Conf., Lexington, Ky. p. 27-30.

Zito, S.W., T.R. Konsler, and E.J. Staba. 1984. Soil and mulch effects on ginsenosides in American ginseng plants. Proc. 4th Intl. Ginseng Symp., Daejeon, Korea. p. 57-62.

Zito, S.W., J. Cheung, T.R. Konsler, and E.J. Staba. 1986. The effect on ginsenoside content of American ginseng (Panax quinquefolium L.) by type of bed mulch and by plant spacing through seven growing seasons. Proc. 7th N. Amer. Ginseng Conf., Delhi, N.Y. p. 201210 . 